to era aplicado sobre o dente e o brilho, restabelecido com discos de lixa e pedra-pomes.

Em 1983, BAUMGARTNER e colaboradores demonstraram que três aplicações da mistura microabrasiva (ácido clorídrico $36 \%$, peróxido de hidrogênio $30 \%$ e éter dietílico) por 5 minutos, seguidos de mais 15 segundos de polimento com disco de granulação fina sob baixa pressão, em pré-molares humanos não produzia nenhum efeito ou dano pulpar histologicamente perceptíveis dentro de até 19 dias de acompanhamento.

No ano de 1986, CROLL e CAVANAUGH (1986a) estabeleceram alguns critérios para um tratamento de correção estética de manchas do esmalte. Para estes autores, o tratamento deveria apresentar resultados permanentes; causar insignificante perda de estrutura dental; não causar danos à polpa e aos tecidos periodontais; requerer o mínimo tempo de tratamento; ser de fácil tolerância para o paciente e ser de fácil realização para o dentista. No mesmo trabalho, eles também propuseram uma nova técnica, na qual a abrasão controlada era feita com uma pasta de ácido clorídrico a $18 \%$ e pedra-pomes. A pasta era aplicada sobre o esmalte com uma espátula de madeira, atritando-se a superfície do dente durante 5 segundos, em seguida lavava-se com água por mais 10 segundos. Este procedimento era repetido por 12 a 15 vezes. Os mesmos ainda estabeleceram alguns cuidados a serem tomados durante o procedimento, tais como: selamento com verniz das margens do lençol de borracha; óculos de proteção para o paciente, profissional e assistente; aspiração instantânea da água de lavagem para não contaminar outras áreas; não aplicar a pasta com taça de borracha em baixa rotação; colocação de um campo de proteção sobre o paciente e neutralização da solução microabrasiva com pasta de bicarbonato de sódio após o procedimento.

Em uma continuação de seu trabalho, publicada: no mesmo ano, CROLL e CAVANAUGH (1986b), ainda mencionaram que qualquer mancha intrínseca do esmalte pode ser removida com a técnica desenvolvida por eles. Basta que esta mancha se restrinja à camada superficial.

Em pesquisa posterior, CROLL e CAVANAUGH (1986c), determinaram que não existe razão para que as manchas reapareçam quando se remove com sucesso o tecido defeituoso do esmalte e a característica natural deste é restabelecida com o polimento e com a remineralização natural do dente. Neste trabalho, eles apresentam fotografias de pacientes com resultados de 6 meses após o tratamento sem retorno das manchas. Os autores ainda relatam que não apenas testemunharam a permanência do resultado, mas, na maioria dos casos, puderam perceber uma melhora ainda maior com o passar do tem- po. A superfície tratada apresenta-se mais lisa e brilhante após 6 meses se comparada com o resultado imediato à microabrasão.

Em 1989, a partir de uma pesquisa de CROLL (1989), desenvolvida em dentes humanos extraídos, para determinar o ácido ideal, a melhor concentração e o melhor agente abrasivo com tamanho ideal das partículas, reunidos em uma pasta que fosse facilmente solubilizada em água, foi lançado no mercado, um produto comercial composto por ácido clorídrico a $10 \%$ e pedra-pomes. O kit para microabrasão ainda continha espátulas especiais para aplicação manual e taças de borracha para serem usadas em baixa velocidade.

KENDELL (1989), avaliou a perda de esmalte com cinco aplicações de 5 segundos do composto microabrasivo desenvolvido por CROLL (1989), constatando uma perda média de $46 \mu \mathrm{m}$, na face vestibular, para os dois terços incisais de incisivos centrais superiores. Para o autor, a remoção desta quantidade de esmalte, nesta região, pode ser confortavelmente tolerada, mas a remoção de quantias similares na vestibular do terço cervical pode resultar em sensibilidade dentinária.

CROLL, em 1990, avaliou os efeitos de um produto comercial à base de ácido clorídrico a $10 \%$ na gengiva humana e pode concluir que uma exposição da mucosa ao ácido, de 15 segundos de duração, seguidos por 30 segundos de lavagem com spray águal ar, se mostrou incapaz de lesar o tecido. Contudo, 30 segundos de exposição ao composto microabrasivo originaram úlceras no tecido gengival que cicatrizaram sem deixar seqüelas após 7 dias.

Em 1991,CROLL determinou o que seria um sistema ideal para microabrasão do esmalte:

Ácido de baixa concentração para aplicação segura;

Abrasivo de grande dureza capaz de microabrasionar o esmalte quando misturado ao ácido;

- Abrasivo com partículas pequenas que permitissem um polimento do esmalte sem apresentar riscos ou ranhuras;

- Pasta de consistência que não permitisse o extravasamento do ácido através do isolamento e solúvel em água para facilitar sua remoção da superfície dentária;

Aplicação com taça de borracha em rotação muito baixa para prevenir respingos da pasta e tornar o procedimento seguro e de fácil e rápida execução;

DONLY e colaboradores, em 1992, observaram através de microscopia eletrônica de varredura os efeitos da técnica de microabrasão sobre o esmalte. A técnica cria uma camada superficial altamente polida, densamente compactada e mineralizada que apresenta graus de refração e reflexão da luz que possibilitam a camuflagem de pequenas imperfeições no esmalte subjacente. Não foram observadas diferenças entre as técnicas de microabrasão; microabrasão seguida de fluoretação e microabrasão, fluoretação e estocagem em saliva artificial por três meses.

A perda de esmalte em dentes submetidos à técnica de microabrasão com 10 aplicações de 5 segundos de ácido clorídrico $10 \%$ mais pedra-pomes foi avaliada por TONG em 1993. Os resultados apresentados, foram de uma perda de $160 \pm 30 \mu \mathrm{m}$. Tendo em mente que a espessura de esmalte no terço médio da face vestibular de incisivos é em torno de $2,5 \mathrm{~mm}(2500 \mu \mathrm{m})$, esta perda foi considerada bastante pequena.

MONDELLI (1995a) propôs uma nova pasta para microabrasão, utilizando ácido fosfórico a $37 \%$ com pedra-pomes na proporção de 1 para 1 , esse novo método possuía as seguintes vantagens: disponibilidade do ácido nos consultórios odontológicos devido ao seu grande emprego nos procedimentos restauradores, consistência adequada e segurança, pois é menos lesivo em caso de ocorrer algum contato acidental com a pele, mucosa ou olhos. Para a realização da microabrasão, os autores sugerem a utilização de um cone de borracha ou de uma ponta de borracha abrasiva, para polimento de compósitos, em baixa rotação (500 r.p.m.), seguindo as mesmas recomendações da técnica com ácido clorídrico (isolamento absoluto, aplicação da pasta por 10 segundos e lavagem com spray água/ar por 20 segundos) a pasta poderia ser reaplicada de 5 a 10 vezes. Após a conclusão da microabrasão, realiza-se o acabamento da superfície com disco de granulação extrafina e polimento com pasta para polimento de restaurações de resina composta aplicada com taça de borracha.

\section{MECANISMO DE AÇÃO}

Quanto ao mecanismo de ação da microabrasão elocubra-se que o ácido penetra na porção orgânica do esmalte, com pouco efeito sobre os prismas, removendo as manchas localizadas na estrutura orgânica. O outro efeito é o do abrasivo, que altera a camada mais superficial do esmalte, removendo parte da estrutura defeituosa e fazendo com que uma grande porção de mineral permaneça compactada sobre o dente, formando uma densa e polida camada na superfície, que apresenta graus de reflexão e refração da luz diferentes de uma superfície não tratada. Esse efeito óptico seria, então, responsável pela camuflagem de manchas da camada subsuperficial. Além disso, a rehidratação com saliva favorece esse fenômeno óptico (DONLY 1997).

Destes dois mecanismos de atuação, de acordo com CROLL 1989, o principal res- 
ponsável pela remoção das manchas é a abrasão limitada do esmalte e o decorrente efeito óptico, mais do que a dissolução do esmalte pelo ácido.

\section{INDICACÕES}

A técnica de microabrasão encontra-se indicada para qualquer caso em que as manchas ou defeitos do esmalte encontrem-se restritos à camada mais superficial (CROLL e CAVANAUGH, 1986b). Por esse motivo, as indicações listadas a seguir não são arbitrárias, podendo haver situações nas quais não se obtém resultados satisfatórios devido a profundidade das manchas:

- Hipoplasia adquirida por: (a) infecção periapical do decíduo; (b) trauma direto por intrusão do decíduo; (c) causas sistêmicas como hipovitaminoses $\mathrm{A}$ ou $\mathrm{C}$, sarampo,varicela, rubéola, escarlatina, hipocalcemia por ausência de vitamina $D$ e intoxicações como fluorose* (ALVARES e TAVANO, 1993);

- Hipoplasia congênita em indivíduos portadores de sífilis congênita (ALVARES e TAVANO, 1993);

- Hipoplasia hereditária ou amelogênese imperfeita que resulta em esmalte hipoplásico, hipomineralizado ou hipomaduro, podendo se apresentar sem prismas (duro e fino), com prismas irregulares e friáveis ou com cristais de apatita incompletos, sendo facilmente perfurado e lascado com uma sonda (ALVARES e TAVANO, 1993).

- Lesões de cárie não cavitadas e inativas (MONDELLI, 1995b);

- Lesões de cárie não cavitadas que se remineralizaram pigmentadas por marrom ou amarelo e estejam inativas (MONDELLI, 1995b);

- Manchas cremes, brancas ou amarelas de causa desconhecida (MONDELLI, 1995b).

\section{VANTAGENS}

A microabrasão do esmalte apresenta as seguintes vantagens segundo MONDELLI (1995b):

- Resultados imediatos e permanentes;

- Mínima perda de estrutura dental;

- Não requer anestesia;

- Não causa danos à polpa e tecidos periodontais adjacentes;

- Requer pouco tempo de tratamento;

- Não exige preparo cavitário e emprego de material restaurador;

- Fácil execução;

- Baixo custo

Não causa sensibilidade pós-operatória.

\section{A TÉCNICA}

De acordo com a literatura (BARATIERI, 1993; CROLL, 1989; CROLL e CAVANAUGH, 1986a; MONDELLI, 1995a; TONG, 1993), pode-se utilizar as misturas de pedra pomes com ácido clorídrico a 10 ou $18 \%$ ou com ácido fosfórico a $37 \%$, sendo que a última apresenta a vantagem de ser preparada diretamente no consultório. A técnica é a mesma para as duas pastas e a seguir está apresentada uma compilação das técnicas de BARATIERI (1993) e MONDELLI (1995a):

1. Obtenção do consentimento, por escrito, do paciente ou responsável.

2. Profilaxia do esmalte dental com pasta profilática.

3. Aplicação de uma pasta protetora (antiinflamatório em orabase) na mucosa do paciente - gengiva e lábios - para evitar lesões pela ação do ácido.

4. Proteção das roupas do paciente com avental plástico.

5. Utilização de óculos de proteção pelo dentista, pelo assistente e também pelo paciente.

6. Isolamento absoluto dos dentes em questão com uma correta invaginação do dique para dentro do sulco gengival e colocacão de amarrias em todos os dentes isolados.

7. Realização de um selamento da interface dente-dique com verniz cavitário à base de copal.

8. Justaposição de uma pasta espessa de bicarbonato de sódio e água sobre o dique junto ao colo dos dentes para neutralizar a ação do ácido em caso de necessidade.

9. Aplicação de uma pequena porção do abrasivo na área afetada e adjacências. Essa etapa pode ser realizada com ponta de borracha abrasiva para polimento de resina de coloração branca ou cinza, com taça de borracha para polimento de resina ou com espátula de madeira. A aplicação deve se estender por 10 segundos, seguindo-se 20 segundos de lavagem da estrutura dental com spray de água e ar.

10. Realização de 12 a 16 aplicações numa mesma sessão. Se após as mesmas, o resultado não for satisfatório, entende-se que a mancha é muito profunda e a técnica deve ser suspensa. Convém salientar que, para se obter um bom resultado estético, não há necessidade de recuperar totalmente em profundidade a mancha hipoplásica. É importante ressaltar ainda, que originalmente, CROLL (1989) recomendou, no máximo, 12 aplicações de 5 segundos. No entanto, tra- tando 408 dentes através desta técnica, BARATIERI (1993) observou que o dobro do tempo de aplicação da pasta, além de não promover desgaste exagerado, acelera e melhora os resultados. Verificou também que muitas manchas que não desapareciam com 12 aplicações, começavam a desaparecer na décima quarta aplicação e sumiam por completo na décima sexta. Dessa forma, quando a mancha não desaparece após 16 aplicações, o tratamento deve ser interrompido, pois trata-se de uma mancha profunda e sua remoção resultaria em desgaste exagerado. De acordo com CROLL (1989), $25 \%$ das manchas de fluorose são profundas e não respondem bem a esse tipo de tratamento.

11. Umedecimento do dente para melhor visualização da eficácia da microabrasão, o que indicará quando parar.

12. Polimento do esmalte com discos de granulação extrafina e pasta profilática fluoretada em baixa rotação.

13. Aplicação de um gel de fluoreto de sódio por 4 minutos. 0 emprego de flúor fosfato acidulado é contra-indicado para pacientes que apresentam dentes restaurados com resinas compostas ou porcelanas, pois o baixo $\mathrm{pH}$ deste pode atacar as partículas de carga das resinas e a superfície da porcelana, comprometendo a estética das restaurações. Nestes pacientes deve-se aplicar um gel de flúor neutro.

14. Indicação de bochechos diários com fluoreto de sódio a $0,05 \%$ para estimular a remineralização, uma vez que a deposição de íons cálcio e fosfato da saliva, potencializada pela ação do flúor, favorece e mantém o resultado estético.

15. Orientação do paciente para retardar por algumas horas o contato com substâncias que contenham corantes (cigarro, chá, café, refrigerantes). Também deve-se orientá-lo quanto à possível sensação de aspereza que o esmalte poderá apresentar, a qual deverá desaparecer em torno de 7 dias.

16. Avaliação uma semana após o tratamento.

\section{AS MAIORES POLÊMICAS}

Segundo CROLL 1989, estas são as dúvidas mais frequientes de profissionais que assistem palestras sobre microabrasão. As respostas para estas polêmicas foram elaboradas pelo mesmo autor com base na literatura científica, em suas pesquisas e, ainda, em sua experiência clínica com a técnica.

1. Existe sensibilidade térmica pós-operatória nos dentes tratados?

* Dependendo do nível de fluoreto na água de abastecimento, existe uma faixa extensa de variaçôes no aspecto dos dentes, desde alterações discutíveis, caracterizadas por manchas brancas ocasionais no esmalte, até intensas modificações, mostrando facetas e coloração castanha da superficie, com tendência para o desgaste e. mesmo. para a fratura do esmalte (SEBBEN 1997). Dessa forma, quanto mais severa a intoxicação, menores as chances de se obter resultados satisfatónos com o procedimento microabrasivo. 
Nenhum de seus pacientes, de qualquer idade, relatou sensibilidade ou algum outro sintoma de agressão pulpar.

2. A superficie de esmalte tratada torna-se mais suscetível à cárie?

Além de não terem sido observadas cáries em dentes tratados, as superfícies microabrasionadas adquirem um aspecto brilhante e lustroso com o passar do tempo.

3. O que causa a formação dessa superficie brilhante com o passar do tempo?

Para o autor a ação ácido-abrasiva da pasta confere um polimento muito fino à camada superficial do esmalte, que, conforme ocorre a remineralização do dente, desenvolve uma textura brilhante semelhante a vidro. Além disso, os dentes tratados aparecem livres de placa. É possível que a superfície se torne tão lisa a ponto de dificultar a formação da película adquirida, o que inviabilizaria a adesão bacteriana. Tendo em vista essa hipótese, o autor defende que as superfícies microabrasionadas deveriam ser estudadas em diferentes intervalos de tempo após o tratamento, para determinar se diminui a formação da película e o acúmulo de placa bacteriana devido ao efeito de polimento da abrasão.

4. O ácido pode se difundir através do esmalte até a junção amelo-dentinária, causando lesão pulpar?

Não existem estudos para determinar se o ácido clorídrico a $18 \%$ pode penetrar completamente no esmalte oferecendo algum risco aos odontoblastos. Contudo, em 1977, GRIFFEN e colaboradores testaram 3 substâncias (peróxido de hidrogênio a 30\%, ácido clorídrico a $36 \%$ e uma mistura destes dois elementos com éter dietílico), marcadas com um isótopo radioativo de fósforo, e nenhuma das soluções penetrou o esmalte até a junção amelo-dentinária. Os mesmos autores ainda mostraram que nenhuma destas substâncias aumenta a permeabilidade do esmalte ou da dentina. Entretanto, existem estudos que relatam a penetração dos agentes clareadores no esmalte, na dentina e até mesmo na câmara pulpar (CARDOSO e VIEIRA, 1997;HANKS, 1993).**

5. Qual a quantia exata de esmalte que é removida?

TONG (1993) reportou uma perda de $160 \pm 30 \mu \mathrm{m}$ em 10 aplicações de 5 segundos do composto ácido-abrasivo com baixa rotação. Na prática, a quantia exata que é removida é irrelevante, desde que permaneça uma camada suficiente de esmalte para exercer função e aparência normais.

6. Podem ser usados instrumentos rotatórios de corte como brocas diamantadas ou carbide ou discos abrasivos para remover manchas do esmalte com resultados equivalentes?

A eficácia não será a mesma. Quando um instrumento rotatório de corte é aplicado no esmalte, é comum que ocorra alteração visível na forma da superfície, não importando quão cuidadosamente foi realizado o tratamento.

7. Previamente ao tratamento, como se sabe qual a profundidade da mancha e quando se deve abandonar a microabrasão e considerar a restauração?

É óbvio que manchas intrínsecas como as de tetraciclina e hemossiderina, ou qualquer outra em dentina, não podem ser removidas com microabrasão. Entretanto, é, muitas vezes, difícil determinar se a mancha é suficientemente superficial para correção com microabrasão. Já se conseguiu observar que as manchas marrons são, na maioria dos casos, superficiais o suficiente para serem removidas por esse método, e cerca de $75 \%$ dos defeitos brancos também. Além disso, em muitos casos, as manchas brancas podem ser parcialmente removidas, conseguindo-se uma correção satisfatória, que, em alguns pacientes, ainda melhora mais conforme ocorre a remineralização do dente. É importante que os resultados sejam avaliados com os dentes umedecidos, pois as manchas tendem a ficar mais proeminentes em uma superfície seca.

A microabrasão deve ser abandonada quando não forem obtidos resultados satisfatórios com até 12 aplicações do composto (ou 16 aplicações, segundo BARATIERI, 1993). Nesses casos as manchas são muito profundas e requerem tratamento restaurador.

8. Caso não se consiga sucesso com a microabrasão, devido à profundidade da mancha, a superficie do esmalte ainda estará apta para receber uma restauração com resina composta?

Sim, e será necessário que se faça um desgaste com uma broca diamantada para expor estrutura virgem de esmalte para que o ácido fosfórico possa agir corretamente. A microabrasão previamente realizada não interferirá em nada no sucesso da restauração.

\section{CONCLUSÕES}

Em se tratando de um assunto que envolve desgaste de estrutura dentária, num contexto onde a máxima preconizada é a opção por condutas conservadoras, parece bastante lógico que surja uma certa controvérsia com relação à utilização da técnica de microabrasão do esmalte. Entretanto é interessante que se avalie a microabrasão sob esse mesmo ponto de vista conservador, pois apesar de resultar em certo desgaste de estrutura dentária, esta técnica encontra sua principal indicação em casos nos quais se deseja evitar procedimentos mais invasivos como as coroas cerâmicas ou metalo-cerâmicas e as facetas de porcelana ou resina composta, que, sem dúvida, resultam em perda muito maior de tecido dentário (CARDOSO e VIEIRA, 1997; MONDELLI, 1995b).

Tendo em vista esses fatos, é natural que se encontre, ao realizar uma revisão de literatura, trabalhos que apontem a microabrasão como uma técnica eficaz, segura e conservadora (HEYMANN, 1997; MONDELLI, 1995b) e outros que considerem esta técnica um tanto invasiva e que deva ser utilizada com muita cautela (CARDOSO e VIEIRA, 1997). HEYMANN (1997) ainda relata que a microabrasão é um procedimento com tempo suficiente de comprovação clínica de sua eficácia e segurança.

Nos casos em que, através da microabrasão, não for possível o total restabelecimento da estética, pode-se ainda partir para um tratamento restaurador (preparo da área, condicionamento ácido do esmalte e aplicação de um sistema restaurador adesivo) sem qualquer interferência negativa no resultado da restauração (CROLL, 1989; MONDELLI, 1995b). Para SEBBEN (1997), a remoção, mesmo que parcial, da mancha auxilia na obtenção de resultados estéticos mais satisfatórios na execução de facetas de resina composta ou porcelana.

Com relação à técnica em si, pode-se dizer que já houve uma grande evolução durante a década de 90, apresentando maior segurança no procedimento tanto para 0 paciente como para os profissionais. Como exemplo, pode-se relatar a técnica que substitui o ácido clorídrico a 10 ou $18 \%$ pelo ácido fosfórico a $37 \%$. Apesar do primeiro ter se mostrado de ótima eficácia com um número reduzido de aplicações, o ácido fosfórico parece ser uma alternativa mais

** Em razão dessa controvérsia encontrada na literatura sobre o efeito de agentes clareadores sobre a polpa e também devido ao fato de não ter sido encontrado um trabalho que avaliasse os efeitos da técnica de microabrasão nos moldes em que é apresentada neste trabalho, torna-se dificil assumir uma posição definitiva com respeito a este tópico. Todavia, existem dois pontos que pesam a favor da segurança da técnica de microabrasão. $O$ primeiro é a grande experiência clínica que se tem com a mesma, onde não são relatados na literatura casos de lesão pulpar. Por último, sabe-se que o principal agente da técnica é a abrasão controlada da camada mais superficial do esmalte, tendo o ácido, um efeito apenas secundário (CROLL, 1989). Diferentemente das técnicas de clareamento, onde a ação química é a única responsável pelo resultado clínico e, por isso, são utilizadas substâncias mais concentradas e, por conseqüência com maior poder de penetração. 
segura, igualmente eficiente e prática, por sia disponibilidade nos consultórios odontológicos (MONDELLI, 1995b).

\section{ABSTRACT}

Objective: Having in mind the growing value that is given to esthetic procedures it has been carried out a literature review about the main polemics that goes around Enamel Microabrasion technique. Action mechanism: the microabrasion compound modifies light refraction and reflection indexes producing an optical effect which allows the camouflage of the subsurface stains. Indications: the technique is indicated to remove any stain, since it is restrict to the most superficial layer of enamel. Advantages: immediate and permanent results with minimum loss of dental structure. Technique: with all care steps taken, a mixture of hydrochloric acid or phosphoric acid and pumice is applied to dental surface for 12 to 16 times, during 10 seconds each application. The application can be done manually or with the help of a low rotation hand-piece. Conclusions: the enamel microabrasion is an effective, safe and conservative technique if compared with other alternatives available. However, some authors affirm that it must be very carefully used because of enamel loss and risks of lesion by the acid.

\section{KEYWORDS}

Esthetic, Mottled Enamel, Enamel Microabrasion.

\section{REFER ÊNCIAS BIBLIOGRÁFICAS}

ALVARES, L.C.; TAVANO, O. Curso de radiologia em odontologia. 3 . ed. São Paulo: Santos, 1993. 248p. Cap.5:, p.192-4, 1993.

BARATIERI, L.N. et al. Clareamento dental. São Paulo: Santos, 1993. 176p. Cap.6: , p.37-9.

BAUMGARTNER, J.C.; REID, D.E.; PICKETT, A.B.. Human pulpal reaction to the modified McInnes bleaching technique. J. Endod., Baltimore, v.9, n.12, p.527-9, Dez.1983.

CARDOSO, S.0.; VIEIRA P.A.A. Efeitos adversos da técnicas de clareamento de dentes vitalizados sobre a estrutura dental e periodonto de proteção. Rev. Esc. Farm. Odont. Alfenas, Alfenas, n.19, p.19-26, jan./dez. 1997.

CHRISTENSEN, J.G. How the trend to elective dental procedures influences vour practice. J. Am. Dent. Assoc. Chicagro. 129 . n.3. p.355-6. Mar. 1900.
CROLL,T.P. A case of enamel color modification: 60 year results. Quintessence Int., New Malden, v.18, n.7, p.493-95, July 1987.

CROLL,T.P. Effect of enamel microabrasion compound on human gengiva: report of a case. Quintessence Int., New Malden, v.21, n.12, p.95963, Dec. 1990.

CROLL,T.P. Enamel microabrasion. Chicago: Quintessence, 1991. 102p.

CROLL,T.P. Enamel microabrasion: the technique. Quintessence Int., New Malden, v.20, n.6, p.395-400, June 1989.

CROLL, T.P.; CAVANAUGH, R.R. Enamel color modification by controlled hydrochloric acid-pumice abrasion. I. Technique and examples. Quintessence Int., New Malden, v.17, n.2, p.81-7, Feb. 1986a.

CROLL, T.P.; CAVANAUGH, R.R. Enamel color modification by controlled hydrochloric acid-pumice abrasion. II. Further examples. Quintessence Int., New Malden, v.17, n.3, p.157-64, Mar. 1986b.

CROLL, T.P.; GAVANAUGH, R.R. Hydrocloric acid-pumice enamel surface abrasion for color modification: results after six months. Quintessence Int, New Malden, v.17, n.6, p.335-41, June $1986 \mathrm{c}$.

DONLY, K.J.; O'NEILL, M.; CROLL, T.P. Enamel microabrasion: a microscopic evaluation of the "abrosion effect". Quintessence Int., New Malden, v.23, n.3, p.175-9, Nov. 1997.

GRIFFEN, R.G. et al. Effects of solutions used to treat dental fluorosis on permeability of teeth. J. Endod., Baltimore, v.3, n.4, p.139-43, Apr. 1977.

HANKS, C.T. et al. Cytotoxicity and dentin permeability of carbamide peroxide and hydrogen peroxide vital bleaching materials, in vitro. J. Dent. Res., Washington, v.72, n.5, p.931-38, May 1993.

HEYMANN, H.O. Nonrestorative treatment of discolored teeth: reports from na international symposium. J. Am. Dent. Assoc., Chicago, v.128, n.6, p.710-2. June 1997.

KEYDELL. R.L. Hydrochloric acid removal of brown fluorosis stains: clinical and scanning electron micrographic observations. Quintessence Int., New Malden, v.20, n.11, p.837-9, Nov. 1989.

McCLOSKEY, R.J. a technique for removal of fluorosis stains. J. Am. Dent. Assoc., Chicago, v.109, n.7, p.63-4, July 1984 .

McINNES, J. Removing brown stain from teeth. Ariz. Dent. J., Phoenix, v.12, n.4, p. 13-5, May 1966.

MONDELLI, J. et al.. Microabrasão com ácido fosfórico. Rev. Bras. Odontol., Rio de Janeiro, v. 52, n.3, p.20-2, maio/ jun. 1995.

MONDELLI, R.F.L. et al. Microabrasão do esmalte. CECADE News, Bauru, v.3, n.2, p.6-11, maio/ago. 1995.

NASH, R.W.; RADZ, G.M. Microabrasion - a conservative approach to removing surface staining. Dent. Econ., Tulsa, v.85, n.6, p.17-22, June 1996.

PAPAKIRITSIS, M.G. Removal of enamel surface stains using a new material. J. Prosth. Dent., St. Louis, v.71, n.5, p.539-40, May 1994.

SEBBEN, C. et al. Clareamento de dentes permanentes com fluorose pela técnica de microabrasão. Rev. Assoc. Paul. Cir. Dent., São Paulo, .51, n.1, p.66-9, jan/fev. 1997.

TONG, L.S.M. et al. The effects of etching, micro-abrasion, and bleaching on surface enamel. J. Dent. Res., Washington, v.72, n.1, p.67-71, Jan. 1993.

Endereço para correspondência: Suzana Werner Samuel Fac. Odontologia UFRGS Rua Ramiro Barcelos, 2492 Porto Alegre - RS - CEP: 90.035-003 e-mail: samuelsp@adufrgs.ufrgs.br 